\title{
IDEOLOGIA E DISCURSOS SOBRE TRABALHO, EDUCAÇÃO E SAÚDE NOS DESCRITORES EM CIÊNCIAS DA SAÚDE
}

\author{
IDEOLOGY AND DISCOURSES ABOUT WORK, EDUCATION AND \\ HEALTH IN THE DESCRIPTORS OF THE HEALTH SCIENCES \\ IDEOLOGÍA Y DISCURSOS SOBRE TRABAJO, EDUCACIÓN Y SALUD \\ EN LOS DESCRIPTORES EN CIENCIAS DE LA SALUD
}

Creuza Stephen Figueira ${ }^{1}$

Resumo Este artigo analisa o instrumento de indexação e recuperação da informação denominado Descritores em Ciências da Saúde como um objeto ideológico-discursivo, na perspectiva da análise do discurso franco-brasileira. A pesquisa foi realizada entre os anos de 2014 e 2015. Para tal, consideramos as condições históricas em que os Descritores em Ciências da Saúde foram criados e traçamos um paralelo entre determinado aspecto da educação e os significados de alguns verbetes relacionados ao campo trabalho, educação e saúde. Em última instância, procuramos contribuir para a área da biblioteconomia com reflexões sobre discurso e ideologia na leitura, seleção e construção de linguagens documentárias.

Palavras-chave tesauro; glossário; análise de discurso; instrumento linguístico-ideológico; educação profissional em saúde.
Abstract The present article analyzes the indexation and data retrieval tool called Descriptors in Health Sciences (Descritores em Ciências da Saúde, DeCS, in the Portuguese acronym) as an ideological-discursive object, through the perspective of the Franco-Brazilian discourse analysis. The research was performed between 2014 and 2015. In order to do so, we considered the historical conditions in which the Descriptors in Health Sciences were created, and we compared between a particular aspect of education and the meanings of some of the entries related to the field labor, education and health. Lastly, we sought to contribute to the field of library ccience with considerations about discourse and ideology in reading, selection and development of documentary languages.

Keywords thesaurus; glossary; discourse analysis; linguistic-ideological tool; professional education in health. 


\section{Introdução}

Um 'tesauro' é uma linguagem artificial criada com base em termos selecionados e estruturados em determinada área do saber para ser usada na classificação e na indexação ${ }^{2}$ da produção literária de uma área de conhecimento, em geral científico. Os tesauros vêm acompanhados de um glossário, e uma característica relevante é que não permitem ambiguidade. No entanto, o que pretendemos ressaltar neste artigo é que os tesauros, guardando aspectos que aprofundam e disseminam seu alcance, tais como dicionários e gramáticas, podem conformar uma sociedade.

Tal afirmação é comprovável quando se observa que os tesauros, em suas definições, não apenas determinam os termos essenciais dentro de um campo do saber; mais do que isso, selecionam, pela escolha vocabular, o que faz parte ou não daquele campo, apagando disputas existentes nas relações sociais. Assim, o conhecimento que chega à sociedade organizado pela linguagem artificial do tesauro ajuda a conformar nessa sociedade uma visão específica de mundo que, necessariamente, exclui outras.

O glossário do tesauro Descritores em Ciências da Saúde (DeCS) foi tomado aqui como um objeto linguístico-ideológico. Para tal, fizemos uso do campo dos estudos da linguagem, utilizando a teoria da análise de discurso (AD), em sua corrente franco-brasileira, e a da história das ideias linguísticas. Contamos, então, com o aporte teórico fornecido por Michel Pêcheux, Eni Puccinelli Orlandi e Sylvain Auroux. Analisar o discurso implica considerar as relações do sujeito com a linguagem em seu tempo, e para capturá-lo nessa perspectiva, é preciso tomar não somente o que é dito, mas também o que foi silenciado ou não dito. São as condições de produção do discurso, determinadas pelas relações das classes sociais, em dado momento sócio-histórico específico, que condicionarão os sentidos que as palavras (ou o silêncio) terão.

Como os sentidos de um discurso são representativos das relações sociais produzidas em determinadas condições históricas, analisar os significados dos termos do DeCS, com a profundidade que a AD permite, contribui para submetermos à crítica as escolhas efetuadas na composição desse tesauro. Assim, é possível perceber que tais escolhas implicam o próprio DeCS como um instrumento linguístico que quer controlar um vocabulário e estabilizar os significados nas ciências da saúde e na educação em saúde.

Na primeira parte, abordamos o contexto histórico da criação da Biblioteca Regional de Medicina (Bireme), que desenvolveu o DeCS. Em função dos verbetes que analisamos, situamos aqui a educação profissional sob a égide do capital, no que concerne à produção e reprodução da dualidade que estrutura o modo de produção de nossa sociedade. À luz desses dois contextos, vemos como o DeCS configura o conhecimento. 
Em seguida, nos dedicamos à compreensão do tesauro como um objeto linguístico-ideológico, assim como à apresentação do arcabouço teórico que sustenta a análise feita a seguir. Por fim, apresentamos a análise dos termos que compõem o domínio da educação profissional em saúde no DeCS, indicando seu papel nas lutas sociais no campo trabalho, educação e saúde, na perspectiva dos estudos marxistas sobre a língua.

Em nossas considerações finais, ressaltamos o fato de que a dualidade educacional que estrutura a sociedade de classes é necessária para a reprodução do capitalismo, e o DeCS, ao apontar determinados termos como sinônimos, atualiza concepções e/ou apaga sentidos em disputas na sociedade, constituindo-se em um instrumento linguístico-ideológico. A análise aqui efetuada buscou contribuir para o campo da biblioteconomia com reflexões sobre discurso e ideologia no trabalho de leitura, seleção e construção de linguagens documentárias.

\section{A criação da Bireme e os organismos internacionais}

Desde a década de 1950, a movimentação por parte de organismos internacionais e de governos locais no sentido de organizar a informação em saúde na América Latina em uma biblioteca central coincidiu com as mudanças que ocorriam no cenário internacional, em que a chamada Guerra Fria colocava em disputa modelos distintos de sociedades nos campos econômico, social, ideológico, político e tecnológico, polarizando valores sociais-ideológicos distintos, representados pelos Estados Unidos e a antiga União Soviética. A organização da informação nessa área de interesse era estratégica para a produção de novos conhecimentos sobre a região e para um planejamento em larga escala. Os organismos das Nações Unidas, nesse momento, avançavam para influenciar as políticas governamentais, e a criação de uma biblioteca central para organizar e disseminar a informação no campo das ciências da saúde teria "um papel fundamental, sobretudo pela generalização das práticas de assistência técnica, transferência de tecnologias e cooperação" (Pires-Alves e Paiva, 2011, p. 156).

Em março de 1967, foi criada a Biblioteca Regional de Medicina (Bireme) num convênio entre a Escola Paulista de Medicina - hoje denominada Universidade Federal de São Paulo (Unifesp) -, a Organização Pan-Americana da Saúde (Opas)/Organização Mundial da Saúde (OMS), ${ }^{3}$ o Ministério da Educação e da Cultura e o Ministério da Saúde do Brasil. Para tal, três instituições apoiaram essa ideia junto ao governo brasileiro: a própria Opas/ OMS; a Federación Panamericana de Asociasiones de Facultades y Escuelas de Medicina (Fepafem); ${ }^{4}$ e a US National Library of Medicine (NLM) (Opas/ OMS, 2015). ${ }^{5}$ 
A concepção de 'desenvolvimento' de um país, desde a década de 1950, estava atrelada a seus níveis de educação e saúde, de modo que a Opas, como uma agência ligada à Organização das Nações Unidas, se estabeleceu na América Latina para atuar nessas áreas. Nas décadas de 1960 e 1970, a Opas possuía na América Latina numerosos programas estabelecidos com os governos no campo da saúde, da educação e na formação profissional em saúde. Ela também propunha modificar currículos dos cursos de graduação em medicina e dos cursos de saúde pública. No campo ainda da educação, a Opas criou o Programa de Livros-Texto, difundindo literatura especializada para professores e estudantes da área da saúde, e apoiou programas de formação de 'recursos humanos' (Lima, 2002).

Um acontecimento marcante que antecedeu a criação da Bireme foi a reunião de ministros dos países membros da Organização dos Estados Americanos, no começo da década de 1960, em Punta del Este, Uruguai. Nessa reunião, foi assinada uma carta-compromisso para a realização do projeto Aliança para o Progresso. A carta continha dois anexos, com planos decenais para a saúde e para a educação (Paiva, 2004).

A presença efetiva dos Estados Unidos na América Latina, influenciando governos, conduzindo ações, cresce a partir de então alicerçando relações que envolviam várias dimensões da vida social: a economia, a ciência, a cultura, a política, a educação, a saúde. A estratégia de propagandear ideologia e inseparavelmente transferir tecnologias na área da educação, da saúde e da cultura era motivada pelo embate entre as concepções de mundo fundamentadas no socialismo ou no capitalismo. Além disso, desde a Revolução Cubana, os Estados Unidos temiam perder terreno no restante da América Latina. De fato, Arapiraca (1979) afirma que a política externa estadunidense teve início efetivo com a Aliança para o Progresso, conforme se pode ler em parte do discurso do embaixador Viron P. Vaky, Secretário de Estado dos Estados Unidos e Assistente para Assuntos Interamericanos, em Punta del Este:

\footnotetext{
A América Latina, como um todo, é considerada como um elemento muito relevante na estratégia global dos EUA, tanto como aliado internacional quanto como reserva estratégica decisiva de gente e capacidade produtiva (...). A América Latina continua um importante mercado para exportação, aos quais (sic) os EUA vendem maquinaria, bens de consumo e produtos químicos tanto quanto vende a todo Mercado Comum Europeu, e mais do que ao Japão (Arapiraca, 1979, p. 142-143).
}

A importância da reserva estratégica de 'gente' e da ampliação de mercados significava que era isso que o capitalismo precisava para seguir seu curso. Segundo David Harvey (2010, p. 20), um dos principais obstáculos para o contínuo acúmulo de capital na década de 1960 foi o trabalho, que nos Esta- 
dos Unidos e na Europa era bem organizado, razoavelmente bem pago e tinha influência política, ou seja, o capital precisava de acesso a fontes de trabalho mais baratas e mais dóceis.

Seguindo essa lógica, países periféricos, como o Brasil, tiveram as suas condições de dependência econômica ${ }^{6}$ aprofundadas, por meio de uma investida sobre os países da América Latina para ampliar espaço de dominação ideológica. E nesse campo, sob a tutela da Opas e com o apoio dos governos locais e do Estado, foi colocada em curso uma programação para sedimentar nas universidades as concepções de saúde calcadas na visão estadunidense, incorporando seus referenciais teóricos e metodológicos.

Em 1964, realizou-se em Poços de Caldas a IV Conferência Latino-Americana de Faculdades de Medicina, promovida pela Opas e pela Fepafem. Pires-Alves (2006) destaca dois fatos importantes: o primeiro é o discurso do presidente da Fepafem, o chileno Amador Neghme, em que "conferiu destaque aos temas da formação pedagógica dos docentes médicos", além de afirmar que considerava importante "a criação de um 'centro regional de documentação bibliográfica e de intercâmbio bibliotecário"”. O segundo é que "a NLM apresentou oficialmente a proposta de criação de uma biblioteca regional especializada" (Pires-Alves, 2006, p. 3).

Era uma proposição simples: dado um determinado território, apenas uma biblioteca central reuniria as coleções mais completas de periódicos. Todas as demais manteriam coleções básicas e diante de uma demanda não atendida solicitariam à biblioteca central o artigo em formato de cópia. O sistema regional é a repartição de um grande território em 'regiões biblioteconômicas' onde uma biblioteca central é apoiada por subcentros. Na terminologia norte-americana, sistemas regionais eram as partes constitutivas do sistema nacional, liderado pela National Library - a biblioteca central deste sistema. A Bireme, segundo o modelo proposto, seria mais uma biblioteca regional integrada a esta topografia (Pires-Alves, 2006, p. 4).

Desse modo, a ideia de uma biblioteca regional começou a ser concretizada com base no modelo da NLM e tendo-a como coordenadora. Pires-Alves afirma ainda:

O que é importante salientar é que como protagonista decisiva na sua formatação conceitual da Bireme, a National Library of Medicine propôs uma biblioteca regional latino-americana ao mesmo tempo em que fazia gestões junto ao legislativo norte-americano pela criação, sob a sua liderança, do sistema de bibliotecas médicas dos EUA. A solução latino-americana teve mesmo uma certa precedência. Não fora o tempo relativamente longo, entre a proposição (1964) e o acordo final de implantação (1967), e a Bireme teria sido a primeira biblioteca daquele que viria a ser o sistema da NLM. 
Assim, a Bireme foi parte de um movimento da NLM, que transbordava o contexto norte-americano. Concebida para resolver os problemas da informação bibliográfica na América Latina, era também parte da solução para os problemas de uma macrogestão desta mesma informação sob a lógica da NLM. Era para a National Library uma forma de distribuir custos e ajudar a financiar o próprio esforço de desenvolvimento de tecnologias. A NLM negociou o projeto da Bireme a partir de uma indiscutível posição de força, que derivava, sobretudo, da sua condição de exclusividade, dadas a extensão das suas coleções e a sua expertise métodotecnológica. Não haveria Bireme sem ela (Pires-Alves, 2006, p. 4).

Percebe-se, então, que foi sob a lógica da metodologia da NLM que a Bireme começou a ser pensada, fazendo parte de seu sistema. Nesse momento, então, com o apoio da Opas/OMS, da Fepafem e da NLM, as negociações tornam-se mais produtivas e constitui-se finalmente a Bireme, em março de 1967, a qual nasce como uma biblioteca para atender a América Latina, sendo um centro especializado da Opas/OMS, subordinado à NLM, e com o apoio do governo federal brasileiro. Desde sua criação, a Bireme está localizada em São Paulo.

\section{O desenvolvimento do tesauro DeCS e a criação da Biblioteca Virtual em Saúde}

Na década de 1970, a NLM autorizou para tradução e adaptação para o espanhol e o português a sua lista de cabeçalho de assuntos médicos (medical subject headings), conhecida pela sigla MeSH. O chamado cabeçalho de assunto é um termo técnico da biblioteconomia que faz referência às classificações utilizadas na catalogação de itens de um acervo, constituindo uma lista de temas contemplados na biblioteca. A lista $\mathrm{MeSH}$, então, foi constituída com base nos termos predefinidos usados na catalogação e extraídos dos assuntos dos documentos selecionados para constar do acervo da NLM - retratando, dessa maneira, a produção literária dos Estados Unidos na grande área das ciências da saúde.

Em 1985, a Bireme ${ }^{7}$ concluiu a tradução do MeSH, dando origem ao vocabulário estruturado DeCS - Descritores em Ciências da Saúde. Nas décadas seguintes, ele foi acrescido com quatro novas categorias para "permitir melhor indexação da literatura técnica e científica da região" (Bireme/Opas/OMS, 2015).

Em 1998, é lançada a ideia de uma Biblioteca Virtual em Saúde (BVS), e em 1999 a BVS do Brasil tem início. Atualmente, há 34 bibliotecas no âmbito regional, e todas as BVSs utilizam uma metodologia desenvolvida pela Bireme que prevê a utilização do DeCS como uma ferramenta de indexação.

Note-se que as BVSs pertencem a uma rede de bibliotecas virtuais com presença em quase todos os continentes, como se pode ver na Figura 1. 


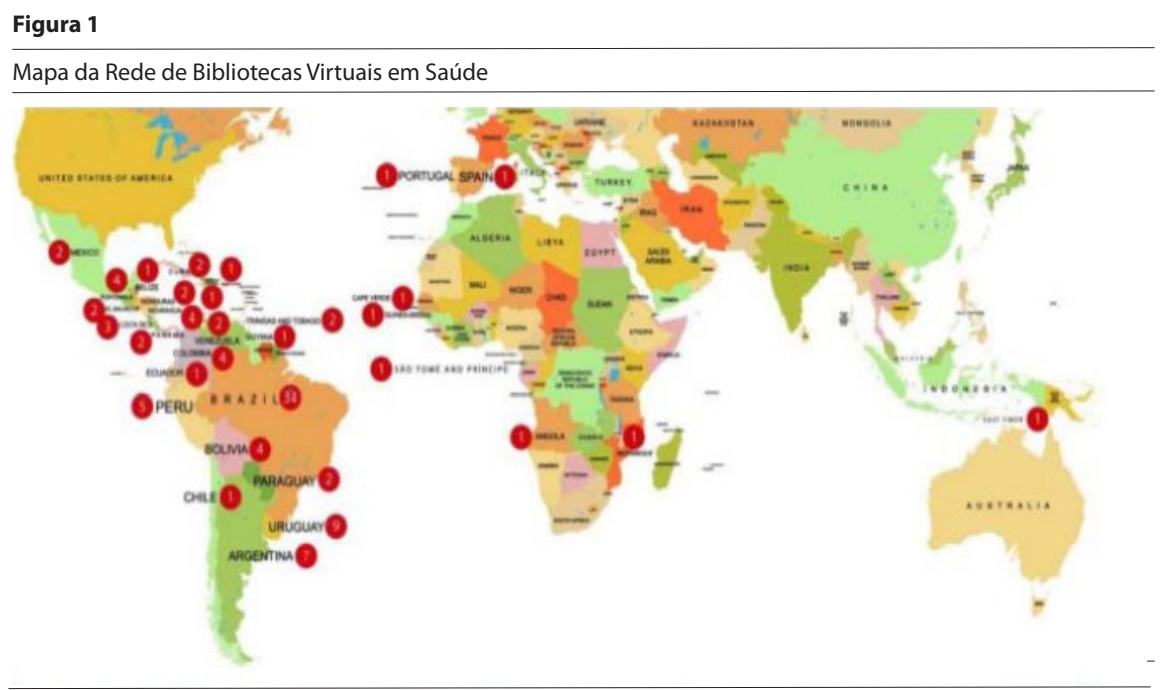

Fonte: Bireme/Opas/OMS, 2018.

Na Figura 1, o algarismo no interior do círculo representa o número de BVSs existentes no país. Essa rede de BVSs é coordenada pela Bireme, como supramencionado, e em 2014 já contava com 116 instâncias em operação regular em 31 países (Bireme/Opas/OMS, 2015).

\section{O DeCS como um instrumento linguístico-ideológico}

Considerar o tesauro DeCS um instrumento linguístico e ideológico é afirmar o seu poder ordenador, num espaço em que estabiliza e legitima sentidos, propagando uma forma de organização para as ciências da saúde. A análise de discurso permite a compreensão do funcionamento da relação existente entre as condições históricas de sua produção, a linguagem (na qual a ideologia se materializa) e os processos de elaboração utilizados por aqueles que são por ele responsáveis.

O processo de concepção das fronteiras de um campo do conhecimento, como é o caso específico da linguagem artificial criada nos tesauros, bem como as definições contidas nele, é embasado por ideologias. Os sujeitos que, no interior das instituições, constroem um tesauro, buscam, em consonância com o posicionamento político da instituição, se inscrever na formação ideológica da classe social que esta representa.

Logo, um tesauro tem uma responsabilidade (uma assinatura) coletiva e jurídica. Nele, as contradições e os confrontos existentes nas relações sociais praticadas na sociedade serão apagados em detrimento de uma definição estabilizada, isto é, aquela escolhida por essa instituição. Tal escolha será justificada pela literatura da área e por outras fontes consolidadas, e ainda por 
uma metodologia que imprime coerência a essas escolhas, suprimindo as ambiguidades nos termos. O campo que se quer representar, então, é recortado e organizado logicamente como se ele fosse 'naturalmente' daquela forma.

Essas escolhas feitas estabilizando cada termo irão se constituir em um vocabulário para controlar a indexação e a pesquisa. Assim, posteriormente, na prática social da indexação - estágio que depende de seleção, leitura e interpretação de textos que vão compor determinado acervo -, os bibliotecários recorrerão ao tesauro e a seu glossário para encontrar meios de representar aqueles textos. Nesse momento, as escolhas políticas demarcadas no tesauro serão reproduzidas, e aqueles que, em diferentes situações práticas, precisarem recuperar aquelas informações utilizarão os termos sem questionar a metodologia usada para selecioná-los e sem, muitas vezes, perceber os sentidos apagados naquele campo.

Dessa forma, podemos afirmar que os tesauros, ao organizarem o conhecimento de uma área, se constituem em instrumentos linguístico-ideológicos que imprimem uma determinada univocidade momentânea e ilusória. Afirmamos que é momentânea porque a dinâmica da vida social impõe modificações às classificações, sendo esse controle uma ilusão estabelecida pelo funcionamento discursivo do objeto em análise. A metodologia supõe, apenas, suprimir ambiguidades e imprimir coerência, mas na realidade cria aquilo que Pêcheux (2009, p. 277) chamou de 'falha no ritual', e os termos silenciados por essa metodologia instituída retornam, fazendo-se de alguma forma significar no campo que, somente ilusoriamente, representa.

\section{A dualidade educacional}

A educação, na sociedade capitalista, anda de mãos dadas com a forma de produzir e reproduzir o capital, a qual gera a vida de forma desigual e desumana, uma vez que a promoção do desenvolvimento humano integral não é um fator prioritário nessa forma social. Assim, a palavra 'educação', para senso comum, tem seu sentido cristalizado e significa apenas 'preparar-se para o trabalho' nos moldes da sociabilidade existente. Somente uma pequena parcela da população consegue obter uma educação mais completa e emancipadora.

A educação profissional no Brasil começa com o processo de transformação de um país agrário para um país industrializado. Ou seja, quando a ideia de 'desenvolvimento' entra na pauta das políticas governamentais, surge a necessidade de escolarizar os trabalhadores e qualificá-los minimamente para a indústria nascente. Assim, percebe-se uma divisão existente na forma de conceber a educação no Brasil e que é constitutiva de uma sociedade de classes. No início da República, quando a educação não era uma política pública, o 
Estado manifestou interesse em ensinar os "órfãos, pobres e desvalidos", para conter a criminalidade advinda da ociosidade que acompanhava o desamparo de menores (Müller, 2009, p. 2). A educação para um ofício foi pensada pela primeira vez pelo Estado para a classe social desprovida de condições de acesso a uma vida digna, ou seja, como uma exceção - os que tinham oportunidade poderiam buscar uma educação intelectual.

Nas décadas de 1930 e 1940, para formar a mão de obra necessária ao crescimento industrial, o Estado criou departamentos, inspetorias dentro dos ministérios e a ideia de ensinar uma profissão para o povo, preparando-o para uma suposta 'sociedade desenvolvida economicamente'. Essas ideias concretizaram-se em decretos-leis e, em 1946, na criação do Serviço Nacional de Aprendizagem Industrial (Senai). Até então, a preocupação com as profissões da área técnica da saúde não existia.

Nos anos 1950, a teoria do capital humano, formulada por Theodore Schultz, afirmava que o investimento em educação e saúde resolveria todos os problemas de iniquidades entre países e indivíduos. No entendimento de Frigotto (2015, p. 5), essa teoria é apenas uma doutrina que não leva em conta “o processo histórico marcado pela desigualdade entre as classes sociais e as nações" e contribuiu, naquele momento, para sedimentar a ideia de ascensão social via méritos, além de servir de justificativa ao Estado para "moldar os sistemas educacionais de acordo com seus interesses de classe" (Frigotto, 2011 , p. 5). O expediente de criar uma formulação que explica a desigualdade social sem considerar a exploração do trabalho de uma classe não é neutro; ele atende aos interesses daqueles que não pretendem efetivamente acabar com a desigualdade e sim dar curso à acumulação de capital.

As reformas educacionais realizadas nas décadas de 1960 e 1970 foram embaladas por essas ideias já anunciadas na Carta de Punta del Este e concretizadas nos Acordos MEC/USAID, que, em 1965, logo após o golpe civil-militar, tiveram seu início. Foram, no total, 12 acordos firmados entre o Ministério da Educação e Cultura e a USAID - Agência dos Estados Unidos para o Desenvolvimento Internacional (Romanelli, 1998).

Esses acordos implementaram profundas mudanças no sistema educacional brasileiro em todos os seus níveis (do ensino fundamental ao superior), bem como nas esferas de seus planejamentos e funcionamentos administrativos. A abrangência desses acordos, segundo Romanelli (1998, p. 213), evidenciou a importância atribuída à educação pelo setor externo "na integração e no posicionamento das sociedades periféricas, no contexto geral do capitalismo internacional". O discurso oficial era de que a educação poderia proporcionar sucesso ao plano político-governamental da ditadura ao promover desenvolvimento, mas, na verdade, temos aqui um reducionismo do conceito de educação, ao considerá-la um bem econômico, uma mercadoria. Além disso, os acordos 
e as reformas implementadas reforçavam junto à classe trabalhadora a mentalidade individualista e competitiva de que os melhores postos na sociedade são para os que mais estudam, mais se especializam, mais trabalham, mais têm méritos, fomentando o espírito capitalista na sua dimensão meritocrática.

Em 1971, a lei n. 5.692 reformou os ensinos de primeiro e segundo graus e tornou a profissionalização no segundo grau compulsória. Segundo Frigotto (2011), essa lei, inspirada na noção de capital humano, deixa clara a ideia de que a dualidade escolar é uma exigência estrutural da sociedade de classes, uma vez que o capitalismo se estrutura com base na acumulação que uma classe social realiza ao explorar a força de trabalho da outra. A dualidade estrutural é a divisão, nas sociedades capitalistas, da formação em dois tipos: a educação intelectual e a educação instrumental, voltada para o trabalho, ou seja, uma para cada tipo de sujeito, segundo suas classes sociais: trabalhadores ou burgueses (Kuenzer, 2007).

A mais impactante mudança que a lei n. 5.692 prescreve, em uma concepção produtivista para a educação, é a de inserir nos currículos, a partir do primeiro grau, disciplinas voltadas para a profissionalização e, obrigatoriamente, formar técnicos no segundo grau. Isso deixa transparecer que a intelectualidade ficaria reservada aos poucos que, seguindo seus estudos, ingressassem na educação superior.

Na década de 1980, assistimos ao fim da ditadura civil-militar, à ascensão dos movimentos sociais, à promulgação de uma nova Constituição. Nessa década, uma das questões que estavam na pauta dos movimentos sociais era justamente a formação do trabalhador. Essa discutida formação, no contexto da incorporação de novas técnicas, redefinindo o modo de produzir num momento de crise do capitalismo, incitava questões decisivas, as quais precisavam ser respondidas. O debate ocorria entre as duas classes antagônicas, e o que estava em jogo era o modelo que se queria criar, tanto no que diz respeito ao acesso universal, público e gratuito quanto na forma de encarar os processos educativos. A proposta dos setores defendendo a classe trabalhadora era de uma educação que rompesse com a dualidade estrutural, que fragmenta a escola e sacramenta a divisão da sociedade, naturalizando a competição desigual.

A interconexão do mundo através de uma grande rede de informações mudou as relações sociais e criou novas possibilidades de desenhos sociais em todos os planos da sociedade, interferindo em organizações políticas, em economias, em culturas. Contudo, paralelamente, discursos de apropriação dessas transformações foram forjados, enquadrando essa nova realidade em interesses que dizem respeito a uma nova face do capitalismo.

A partir da década de 1990, em decorrência do aprofundamento do receituário neoliberal no Brasil e das configurações de uma 'nova divisão internacional do trabalho', ${ }^{8}$ com os mercados globalizados, o capital se estabelece onde encontra mão de obra mais barata. A educação profissional, por sua 
vez, vem se moldando a essas novas exigências de lucro em todos os níveis. A formação educacional em geral adquiriu um aspecto mais aligeirado, para se ter um trabalhador com perfil flexível, capaz de se adaptar às exigências de um mercado frenético, com concorrências acirradas. As instituições educacionais cada vez mais se submetem à lógica neoliberal hegemônica; dessa forma, cresce o distanciamento que há entre um projeto emancipatório e a prática educativa em nossa sociedade.

Em meados dos anos 1990, o Banco Mundial entra em cena apregoando a necessidade de desenvolver uma "cara mais humanizada" para o capitalismo, reconhecendo os efeitos perversos do neoliberalismo em face das críticas vindas de diversos setores (Motta, 2011, p. 43). Nesse momento, no Brasil, um plano para a reforma do aparelho de Estado entra em curso para introduzir modificações no modo administrativo, considerado ultrapassado. Assim, as parcerias entre empresas públicas (ditas inoperantes) e privadas (ágeis e inovadoras) crescem, sobretudo na área da saúde e da educação. Na saúde, as organizações sociais de saúde implementam uma privatização por dentro do Sistema Único de Saúde (SUS); na educação, são criados convênios entre governos e empresas privadas, como o Programa Universidade para Todos (Prouni), por exemplo.

Segundo Frigotto (2011, p. 27), é nesse contexto de luta individual pela sobrevivência, sem proteção de direitos, que nas relações de produção e nas relações sociais "emergem as noções de sociedade do conhecimento, qualidade total, pedagogia das competências, empregabilidade, empreendedorismo e capital social". Esses termos, na verdade, mascaram o sentido concreto da realidade em que se inserem e direcionam a formação da classe trabalhadora às novas necessidades do capital, jogando com valores reconhecíveis, solidificados.

Esse vocabulário introduzido na linguagem corrente, conforme afirmado, serve para mascarar a realidade, além de criar, a médio e longo prazos, um consenso na sociedade, uma vez que o Estado, por meio de programas, colabora para reforçar a ideia de que esses conceitos representam uma saída para as questões apresentadas (Neves, 2010).

De acordo com Motta (2011, p. 42), a Lei de Diretrizes e Bases da Educação (n. 9.394, de 1996) introduz "os arsenais ideológicos da competitividade como fator de inserção do país no mercado mundial e da empregabilidade, justificando o investimento no capital humano, e no desenvolvimento de habilidades para as novas configurações produtivas". O objetivo, então, seria o de pautar a formação do trabalhador para um novo tipo de sociedade em que a tecnologia seria a propulsora de um novo desenvolvimento.

Segundo Kuenzer (2007, p. 1.154), o atual regime de acumulação, dito flexível, "ao aprofundar as diferenças de classe, aprofunda a dualidade estrutural, como expressão cada vez mais contemporânea, da polarização das competências". O aprofundamento das diferenças de classe social a que se 
refere Kuenzer é sentido no aumento da oferta de escolas profissionais. Essa necessidade demonstra, segundo a autora, que a precarização do trabalho, marcada por perdas de direitos sociais, requer da classe trabalhadora conhecimentos diversificados que se encontram disponíveis em cursos ligeiros ministrados à noite ou à distância. Essa dualidade estrutural, a que a maioria da população está submetida e que a classe dirigente nega ao afirmar que estatisticamente a distribuição da educação é mais equânime, na verdade está mais profunda e sedimenta com ela a ideia de que o desenvolvimento de competências é natural. Por isso, o Estado multiplica possibilidades de cursos, traça metas, cria programas através dos quais efetua mil parcerias com o setor privado concretizando, na realidade, o caráter mercadológico que a educação adquiriu nas últimas décadas. Por meio de programas governamentais, verbas públicas alimentam pequenas, médias e grandes corporações financeiras que atuam no mercado educacional, como é o caso da Kroton, a maior do mundo, com mais de um milhão de estudantes (Strecker, 2015), da Anhanguera e do Grupo Anima, entre outras.

\section{A noção de instrumento linguístico e a análise de discurso}

A noção de instrumento linguístico foi desenvolvida por Auroux, que assim conceitua o que denominou de 'gramatização':

Por gramatização deve-se entender o processo que conduz a 'descrever' e a 'instrumentar' uma língua na base de duas tecnologias, que são ainda hoje os pilares de nosso saber metalinguístico: a gramática e o dicionário (Auroux, 2009, p. 65).

Assim, percebe-se que Auroux considera a gramatização uma revolução tecnolinguística que permitiu ao Ocidente uma posição privilegiada em relação ao restante do mundo. O termo 'tecnolinguística' refere-se ao fato de que os instrumentos gramáticas e dicionários são uma tecnologia na qual a matéria-prima trabalhada é a língua e por meio da qual se constituem metalinguagens (Auroux, 2009).

Auroux detalha esse processo de trabalho metalinguístico que aconteceu no Renascimento europeu com a produção de

dicionários e gramáticas de todas as línguas do mundo (e não somente dos vernáculos europeus) na base da tradição greco-latina. Esse processo de 'gramatização' mudou profundamente a ecologia da comunicação humana e deu ao Ocidente um meio de conhecimento/dominação sobre outras culturas do planeta (Auroux, 2009, p. 9). 
Esse grande evento, segundo o autor, constitui-se em uma revolução tecnológica tão importante quanto a revolução agrária do neolítico e a Revolução Industrial. A elaboração do pensamento sobre a língua (as hipóteses levantadas sobre a possibilidade de todas as línguas derivarem de uma única fonte) e a rápida evolução dos estudos depois da imprensa, a tradução (em caracteres latinos, por aproximação de sons) das várias línguas ágrafas existentes (por exemplo: línguas ameríndias) e os estudos comparativos possibilitaram "a constituição de um corpus de exemplos decisivo para a gramatização" (Auroux, 2009, p. 67). Assim, entende-se que as gramáticas e os dicionários, na Idade Média e no Renascimento, não somente proporcionaram o acesso a outras culturas e a outros saberes, mas revolucionaram várias áreas do conhecimento com novas descobertas, preparando a sociedade para mudanças.

Com base na definição de gramatização, fica claro que ela proporciona uma mudança radical na vida social. Dessa forma, entendemos que, à sua semelhança, os tesauros e seus glossários, na prática da indexação, podem modificar a paisagem do campo científico, pois reproduzem a visão que se quer hegemônica. Por isso, podemos afirmar que o tesauro é um instrumento linguístico tanto quanto dicionários e gramáticas.

A essa noção de instrumento linguístico adicionaremos a consideração de que é na prática, em determinado momento sócio-histórico, que os conceitos se constituem e se relacionam e marcam a língua ideologicamente, possibilitando que estudemos sua historicidade.

O discurso pode ser considerado também uma prática. E assim, o dicionário é produto de práticas exercidas em determinadas conjunturas. Segue disso que ele é produzido e, para sua análise, é preciso conhecer suas condições de produção. Como todo discurso, o dicionário tem uma história, ele constrói e atualiza uma memória, reproduz e desloca sentidos, inscrevendo-se no horizonte dos dizeres historicamente constituídos. A Análise de Discurso estabeleceu um quadro teórico e uma metodologia para compreender a constituição histórica dos sentidos. Em meio às ciências da linguagem, a AD caracteriza-se por articular língua, sujeito e história (Nunes, 2006, p. 18).

O discurso é uma prática, porque envolve interação e produção de posicionamentos (não é neutro), em determinadas condições sócio-históricas, por isso é local de manifestação da ideologia. Ao definir as 'condições de produção' do discurso, Nunes (2006, p. 19), citando Pêcheux, afirma que é preciso que se considerem os fatores "externos" à língua para analisarmos o discurso, pois são as formações sociais e os sujeitos que realizam sentidos pela materialidade da língua, provocando diferentes efeitos. 
As denominadas 'condições de produção' a que Pêcheux (1997) se refere, na formulação da $\mathrm{AD}$, são aquelas condições que delimitam histórica e socialmente o sentido determinado de um discurso. Ou seja, o que a AD denomina de condições de produção são as circunstâncias sociais e históricas que contextualizam o discurso, atribuindo-lhe sentido. Nessa perspectiva, o discurso está inserido em uma prática social e possui 'marcas' da classe social em que foi produzido. Essas 'marcas' são ideológicas, de modo que concordamos com Orlandi quando afirma que "a materialidade específica da ideologia é o discurso e a materialidade específica do discurso é a língua" (Orlandi, 2009, p. 16). Isso quer dizer que interesses sociais de uma classe se concretizam na língua, num dado momento histórico, e podem se chocar com interesses de outra classe na prática social.

Pêcheux (1996), em sua teoria materialista do discurso, define o sujeito como aquele que é interpelado pela ideologia. Isso quer dizer que para analisar as produções discursivas precisamos compreender os mecanismos de produção e de reprodução de uma sociedade, considerando nela as lutas de classe ou, dizendo de outra forma, os embates ideológicos. É nesse sentido que ele afirma que "ideologias não se compõem de ideias, mas de práticas" (Pêcheux, 1996, p. 143) materializadas no discurso.

É importante acrescentarmos que também fazem parte das condições de produção as noções de 'memória' e de 'interdiscurso'. Orlandi (2009, p. 33) afirma: "para que minhas palavras tenham sentido é preciso que elas já façam sentido", e é esse fenômeno, o qual envolve a 'memória' e o 'esquecimento', que Pêcheux denomina de interdiscurso. Ou seja, 'interdiscurso' é o diálogo com um discurso de origem "esquecida", em que resta apenas uma ideia naturalizada, independentemente de um enunciado (Pêcheux, 2009, p. 53). Interdiscurso é memória absorvida. Acionando o que é conhecido e que não sabemos como foi parar em nós é que ocorrem os deslizamentos de sentidos. No discurso, podemos observar a presença da ideologia (esquecida) com o que foi selecionado ou apagado ('ideologias').

Nunes (2008) chama a atenção para a importância da análise do discurso documental, definindo-o como aquele produzido por instituições que têm interesses específicos na constituição de arquivos. ${ }^{9}$ Arquivos podem, então, ser entendidos também como uma memória institucionalizada. Essa memória tem relações com o interdiscurso:

o que estamos chamando arquivo é a memória institucionalizada, estabilização de sentidos. No arquivo, o dizer é documento, atestação de sentidos, efeito de relações de forças. Se no interdiscurso há o que se deve dizer, mas também o que se pode dizer e mesmo a possibilidade de se dizer o irrealizado, o arquivo repousa sobre o realizado, menos sobre o que pode e muito mais sobre o que deve ser dito. No arquivo há, assim, um efeito de fechamento. Se o interdiscurso se estrutura 
pelo esquecimento, o arquivo é o que não se esquece (ou o que não se deve esquecer). Se no interdiscurso fala uma voz sem nome (cf. Courtine), no arquivo fala a voz comum, a de todos (embora dividida) (Orlandi, apud Nunes, 2008, p. 89).

Podemos dizer que a teoria da $\mathrm{AD}$, ao explicitar os processos de construção do discurso, permite que sentidos fixados institucionalmente em arquivos sejam conhecidos. Como afirma Pêcheux (1997), é a materialidade da língua, a discursividade do arquivo, que necessitamos reconhecer para que se produza reflexão sobre os efeitos da constituição dessa memória que estabiliza sentidos e os efeitos da leitura de arquivos.

Nesse ponto, podemos lembrar que Pêcheux (2009) se refere ao equívoco da língua para sublinhar que não há sentidos em si, mas que eles se constituem em referência às suas condições de produção. Os sentidos ultrapassam as palavras, podendo sempre ser outros. No entanto, quando a interpretação é interditada - como é caso dos vocabulários controlados de uma linguagem documentária - a estabilização de sentidos é explícita. A interpretação, no caso da construção de uma linguagem documentária, ocorre no momento anterior a sua utilização, isto é, no momento da escolha dos termos que irão representar os conceitos selecionados e de suas definições. Aos usuários - o pesquisador, ao realizar uma busca; o autor, quando procura termos para adicionar uma palavra-chave em seu artigo; as revistas científicas, que estabelecem seu escopo; as bases de dados, que definem um perfil para sua constituição; o bibliotecário indexador - cabe apenas reproduzir aquele termo que foi definido institucionalmente, reproduzindo um posicionamento e controlando novos discursos na sociedade.

Cabe ainda assinalar que o modo de produção capitalista tenta separar a prática científica da prática política, afirmando que o homem, no singular, produz conhecimentos científicos, os quais seriam independentes das relações de produção e da luta de classes. No entanto, conforme afirma Pêcheux (2009, p. 172), "são os homens, em sociedade e na história, isto é, a atividade humana social e histórica", que os produzem. Ou seja, os conhecimentos científicos são produzidos pelos homens dentro de uma sociedade, dentro da História, por isso estão inscritos também na luta de classes. Podemos então afirmar que, embora o discurso científico busque apagar o sujeito, não “há um puro 'discurso científico' sem ligação com alguma ideologia” (Pêcheux, 2009, p. 182).

\section{Educação e trabalho em saúde no DeCS}

O conceito 'educação' em nosso entendimento é o fio condutor do discurso do DeCS para a organização desse recorte referente à educação profissional em saúde: "Educação - Aquisição de conhecimento como resultado de instrução em um curso formal de estudo" (DeCS, 2015). 
Na construção do DeCS, interessou apenas o significado de que educação é o que conseguimos formalmente reforçando ideias contidas na teoria do capital humano. ${ }^{10}$ Esse sentido foi construído historicamente no capitalismo, como apontamos em seção anterior, e encontra-se sedimentado como uma ideologia que confere materialidade ao discurso circulante na sociedade e, por isso, produz (na língua) o efeito de transparência. É o 'já-dito' a que se refere Pêcheux (2009) que compõe o que denomina de 'interdiscurso' - ou seja, um significado que não sabemos como foi parar em nosso entendimento.

O verbete lista como sinônimos de educação os termos 'programas de treinamento; oficinas de trabalho e workshops'. Os termos chamados de sinônimos não são autorizados para serem utilizados na indexação; no entanto, caso se faça uma consulta com um deles, somos remetidos para o termo autorizado, que é educação. Uma linguagem documentária tem a intenção deliberada de disciplinar, de estabilizar um vocabulário que serve aos interesses da classe social que possui o poder regulador do discurso das ciências. Portanto, denominar de sinônimos os termos não autorizados é igualar seus sentidos, silenciando as diferenças existentes. Não definir os ditos sinônimos em seu glossário, nem permitir seus usos na indexação - marcando as diferenças entre cada um deles -, trará reflexos na seleção de material para constituição de acervos e na circulação de arquivos, podendo naturalizar uma redução de significados com reflexos em novas epistemologias. Significa efetivamente, ao longo do tempo, apagar as especificidades contidas nessas conceituações.

Quando o DeCS equipara, em sua definição, educação (formal) com programas de treinamento e oficinas de trabalho, está atualizando seu sentido, pois estes últimos termos são no momento as ações que imprimirão produtividade ao trabalho, para dar continuidade à dualidade estrutural da sociedade, ou seja, para fazer funcionar o capitalismo. No DeCS, essas formas aligeiradas de treinar para o serviço são legitimadas quando equiparadas à educação formal.

Acreditamos também que a opção por um sintagma nominal, isto é, uma estrutura em que não há um termo com a função sintática de sujeito na definição de educação - "aquisição de conhecimento como resultado de instrução em um curso formal de estudo" (DeCS, 2015) -, tenta apagar as condições de produção desse discurso e estabelecer um efeito de verdade em si mesmo, independente. Pêcheux (2009, p. 182) afirma que o sujeito, no discurso da ciência, está "presente por sua ausência, exatamente como Deus está sobre a Terra no discurso religioso". Portanto, esse sintagma nominal é a forma linguística discursiva escolhida para dar ao conceito de educação essa ideia de transparência, a qual se encontra apoiada no interdiscurso, o já-dito e esquecido, estando pretensamente desprovido de uma materialidade externa que indique como foi constituído.

Ao se ampliar um pouco mais o domínio do conceito educação, temos o conceito currículo, assim definido: “Currículo - Conjunto de estudos e práticas 
destinadas a que o aluno desenvolva plenamente suas possibilidades (Diccionario de la Real Academia de la Lengua Española). As matérias constantes de um curso (Dicionário Aurélio)" (DeCS, 2015).

Ao dar voz a dicionários, as instituições Bireme/Opas/OMS tentam referendar com neutralidade seu discurso. Não são elas, sozinhas, que afirmam, mas os dicionários reconhecidos que definem o currículo de maneiras diferentes e complementares. Segundo Nunes (2006), os dicionários, até muito recentemente, eram consultados apenas para se ver o sentido dito correto da palavra. "Assim, não se ensinava o dicionário, pelo contrário, era o dicionário que 'ensinava' como uma autoridade pouco questionada" (Nunes, 2006, p. 7-8). Mas, quando se analisa o discurso de um dicionário ou de um glossário, consideramos que os sentidos se constituem em suas filiações sócio-históricas. Definir o verbete com as palavras publicadas em obras reconhecidas é esperar, por antecipação, que não sejam refutadas, é uma forma de tentar calar outras possibilidades de significação, imprimindo de forma autoritária uma possibilidade apenas para compreensão (e reprodução) do conceito de currículo.

Ao considerar algumas das subdivisões de currículo, para sintetizar, podemos afirmar que a educação, no DeCS, é a aquisição de conhecimentos transmitidos formalmente por matérias de um currículo e suas práticas, utilizando modelos baseados no desenvolvimento de competências e/ou de aprendizagem baseada em resolução de problemas.

A noção de competência, hoje, está vinculada à ideologia mercadológica de aquisição de novas competências em especializações, por meio de cursos de requalificação profissional, incutindo no indivíduo a responsabilidade de se colocar num mercado de trabalho que não tem a possibilidade de absorver todos (Alves, 2009).

$\mathrm{O}$ verbete dedicado à educação profissionalizante ratifica a ideia de treinamento, voltada para uma forma redutora, mecânica e aligeirada de formar para se ter um executor de tarefas: "Educação convencional e treinamento para a prática de uma profissão" (DeCS, 2015).

No DeCS, o credenciamento tem como sinônimos os termos qualificação profissional e qualificação profissional em saúde. Sua definição pode ser vista a seguir: "Credenciamento - Reconhecimento da competência técnica ou profissional através de registros, certificados, licenciamento, admissão em sociedades ou associações, diplomas etc." (DeCS, 2015).

A política social assim definida considera apenas os interesses do Estado, que é aquele que escolhe e determina a execução dos serviços, por isso sua vinculação aos controles formais da sociedade, outra categoria vista na hierarquia do DeCS. A ênfase, portanto, está nos diplomas, nos certificados, nos credenciamentos e nas certificações; a qualificação profissional, dessa forma, fica equiparada a credenciamentos e resume-se a uma competência que pode ser medida, quantificada. 
Fruto da tradução e adaptação para a América Latina de um discurso liberal norte-americano, o DeCS se apoia na garantia de direitos gerados pela legislação do Estado. Podemos afirmar, então, que a visão que imprime é a da classe dominante. Ao definir indiretamente a qualificação profissional como o simples ato de um indivíduo ou de uma empresa possuir certificações e credenciamentos que passam pelos controles formais e podem ser avaliados por métodos quantitativos, apagam-se todos os sentidos das lutas sociais para garantia da assistência à saúde numa prática vivida em sociedade.

Veja-se, por exemplo, a definição encontrada no DeCS para ciência: "estudo de fenômenos naturais por observação, medidas e experimentação" (DeCS, 2015). Daí podemos concluir que as relações sociais não conseguirão ser consideradas e representadas com base nessa concepção de ciência, porque a totalidade social não possui expressão no DeCS. Isto é, não será pela descrição de características e especificações que um descritor será selecionado para dele fazer parte, mas sim por se colocar em algum nível de uma categoria nele preexistente e verificada ou estar em oposição a algo já conhecido, medido, experimentado.

Quando um determinado sentido de qualificação profissional é estabilizado no tesauro DeCS como um sinônimo do credenciamento, definido pelo "reconhecimento de uma competência técnica ou profissional através de medidas" (DeCS, 2015), muitos sentidos diretamente ligados à assistência à saúde, por exemplo, foram silenciados. Somente o aspecto formal foi ali explicitado, deixando de fora seu caráter de relação social complexa, que envolve disputas no campo econômico e político para a formação da classe trabalhadora.

\section{Considerações finais}

O objetivo deste artigo foi, em linhas gerais, analisar alguns verbetes do glossário do DeCS como um objeto discursivo e ideológico, mediante um delineamento teórico traçado com base na análise de discurso e na história das ideias linguísticas.

Ao rever nossa análise, vimos que, no DeCS (2015), a educação é definida

como "aquisição de conhecimentos adquiridos em curso formal de estudos", e ao desautorizar o uso de alguns termos (programas de treinamento, workshops etc.) mas ao mesmo tempo reconhecê-los como sinônimos de educação, ele amplia seu sentido expresso. O que queremos afirmar é que essa extensão de sentidos atualiza o significado dado ao verbete e inscreve o DeCS em uma formação ideológica que tenta separar a prática científica da prática política, na medida em que, em sua parcialidade, representa apenas os interesses do Estado: uma educação voltada para a preparação para o trabalho, a qual, atualmente, exige um trabalhador com conhecimentos e aptidões para dife- 
rentes atividades. Logo, o estudo referenciado na definição do DeCS é aquele conseguido em programas aligeirados.

Da mesma forma, o verbete currículo reafirma a lógica objetivista encontrada na definição de educação, respaldada em dicionários. A aproximação que estabelece com alguns currículos (educação baseada em competências; aprendizagem baseada em problemas), que visam sobretudo preparar o trabalhador para tarefas, reafirma a preocupação do DeCS em estar afinado com o conjunto de propostas governamentais para o campo da educação, trabalho e saúde e aponta para as condições de produção de seu discurso.

Em continuação, vimos que a educação profissionalizante é definida diretamente como um "treinamento para a prática de uma profissão" (DeCS, 2015), em que a educação é equiparada, novamente, ao treinamento. O que interessa nesse recorte dado para a educação profissional no DeCS é uma educação certificada, por isso analisamos o verbete credenciamento.

O credenciamento tem também um sentido objetivo, que é o de certificar, diplomar, reconhecendo a "competência técnica ou profissional" (DeCS, 2015). Nesse verbete, encontramos os termos qualificação profissional e qualificação profissional em saúde como sendo seus sinônimos. No meio educacional, a qualificação é vista como resultado de credenciais obtidas e como processo construído em relações sociais em que o trabalhador acumula saberes tácitos (Guimarães, 2009), sentido reduzido no DeCS ao significado de uma certificação.

Essa análise permite-nos concluir que a forma organizativa (isto é, a sintaxe) do DeCS coloca seu léxico em consonância com a classe dominante, na medida em que não dá espaço para a representação das disputas que acontecem na sociedade, como vimos na análise de alguns dos termos para a educação em saúde. Ao analisarmos esses verbetes, constatamos, muitas vezes, que o estabelecido por lei foi priorizado como uma verdade única, silenciando termos em discussão na sociedade. Por isso, podemos dizer que o DeCS, ao conformar uma dada organização sistemática do conhecimento, regulando um vocabulário, controla também a informação e a língua.

Consideramos que toda sociedade constituída por classes apresenta em sua dinâmica lutas sociais por interesses diversos - e, muitas vezes, antagônicos e se equilibra na necessidade de manutenção da exploração e da dominação expressa em discursos. Portanto, a ideologia materializada no discurso é uma prática a partir de um lugar e de um momento localizados na história. Esse momento determinará o sujeito.

Observamos que o discurso científico do DeCS, com origem em uma biblioteca situada no centro do capitalismo mundial, num momento histórico específico, é fruto dessas condições e com elas dialoga.

Verificamos que o DeCS, podendo até ser permeável e dinâmico em alguns pontos, se fecha em uma lógica estipulada para ser coerente. Nessa 
perspectiva, ao organizar a informação em ciências da saúde reproduzindo em seus verbetes a visão que se quer hegemônica, o DeCS é um instrumento linguístico-ideológico, pois intervém, na prática de seu discurso, na luta que existe na sociedade no campo do trabalho, educação e saúde.

A educação profissional em saúde deveria ocupar, em nosso entendimento, um lugar transversal nas ciências da saúde, pois na prática perpassa todas as suas disciplinas. As concepções de saúde, doença e toda construção de saberes nas especialidades que constituem os campos das ciências da saúde advêm das discussões e das lutas políticas que se dão na sociedade, e reflexões importantes são trazidas pela educação com contribuições preciosas da filosofia, da sociologia e da cultura em práticas que não deveriam ser desconsideradas, como efetivamente observamos que são no DeCS.

Por fim, podemos afirmar que a AD traz novas possibilidades de análises que contribuem para a área da biblioteconomia, tanto no momento de criação de linguagens documentárias quanto no momento de análises de textos para indexação, porque amplia as reflexões que podem advir quando se pensa no ponto de interseção da língua com a história e a ideologia.

Resumen Este artículo analiza el instrumento de indexación y recuperación de información denominado "Descriptores en Ciencias de la Salud" como un objeto ideológico-discursivo, en la perspectiva del análisis del discurso franco-brasileño. La investigación se realizó entre el 2014 y el 2015. A este fin, consideramos las condiciones históricas en las que los Descriptores en Ciencias de la Salud se crearon y trazamos un paralelismo entre determinado aspecto de la educación y los significados de algunos términos relacionados al campo trabajo, educación y salud. En última instancia, buscamos contribuir con el área de la biblioteconomía con reflexiones sobre discurso e ideología en la lectura, selección y construcción de lenguajes documentales.

Palabras-clave tesauro; glosario; análisis de discurso; instrumento lingüístico-ideológico; educación profesional en salud. 


\section{Notas}

${ }^{1}$ Fundação Oswaldo Cruz, Escola Politécnica de Saúde Joaquim Venâncio, Rio de Janeiro, RJ, Brasil.

<creuza.figueira@fiocruz.br>

Correspondência: Fundação Oswaldo Cruz, Escola Politécnica de Saúde Joaquim Venâncio, Av. Brasil, 4.365, Manguinhos, CEP 21040-360, Rio de Janeiro, RJ, Brasil.

${ }^{2}$ Sinteticamente, Lancaster (2004, p. 6) define a indexação como "pontos de acesso mediante os quais um item é localizado e recuperado, durante uma busca por assunto em arquivos, catálogos ou base de dados".

${ }^{3}$ A Opas, a partir de 1948, com a criação da Organização Mundial da Saúde (OMS), agência especializada da Organização das Nações Unidas (ONU), passou a atuar como um escritório regional da OMS para as Américas.

${ }^{4}$ A Fepafem é um organismo não governamental que reúne a quase totalidade das escolas de medicina do continente americano (Fepafem, 2015).

${ }^{5}$ A NLM é a Biblioteca Nacional de Medicina dos Estados Unidos e coordena as bibliotecas regionais existentes. Nas palavras de Pires-Alves (2006, p. 3), “ela é uma instituição líder e modelar", cumprindo esse papel também fora das fronteiras.

${ }^{6} \mathrm{O}$ conceito de dependência encontrado na literatura tem diferentes abordagens. Como não é objeto deste trabalho aprofundar-se nesse campo, nos balizamos pela citação contida no Manifesto comunista: o capitalismo possui "a necessidade de mercados sempre crescentes para seus produtos [o que] impele a burguesia a conquistar todo o globo terrestre. Ela precisa estabelecer-se, explorar e criar vínculos em todos os lugares" (Marx e Engels, 1998, p. 11).

${ }^{7}$ Em 1982, a Biblioteca Regional de Medicina (Bireme) alterou seu nome para Centro Latino-Americano e do Caribe de Informação em Ciências da Saúde, mas conservou a sigla Bireme, preservando, assim, a identidade construída historicamente por seu trabalho.

8"No atual contexto de globalização, a expressão 'nova divisão internacional do trabalho' tem sido usada para designar as mudanças no mercado, na distribuição de capital e das empresas, bem como no fluxo da força de trabalho entre os países, especialmente a relação 'centro-periferia'. Ou seja, a relação países capitalistas desenvolvidos, países emergentes e países pobres ou com pouco potencial competitivo na economia global" (Henk, 1988, apud Pires, 2009).

${ }^{9}$ A palavra 'arquivos' aqui está sendo usada na acepção dada por Pêcheux (1997, p. 63), isto é, a reunião de documentos sob um mesmo assunto.

${ }^{10}$ No momento em que o DeCS foi elaborado, a teoria do capital humano embalava reformas educacionais que anunciavam a escolarização como um remédio eficaz para os problemas da desigualdade social. Atribuir o sentido apenas de conhecimentos adquiridos formalmente se contrapõe à ideia de valorização de saberes adquiridos na prática social. Reconhecer apenas a educação formal e apagar outras noções da educação (não há no DeCS termos como 'educação popular' ou 'educação informal', por exemplo) contribui para sedimentar apenas a ideia de que os conhecimentos válidos são os da escolarização. Na chamada reestruturação produtiva, os saberes tácitos e as competências individuais 
foram incorporados aos programas governamentais para se ter um trabalhador 'flexível' e resolvendo problemas pautados em sua experiência. Workshops e treinamentos passaram a ter no DeCS o mesmo sentido de educação formal, ampliando seu sentido na mesma lógica capitalista de formar trabalhador.

\section{Referências}

ALVES, Giovanni. Reestruturação produtiva, novas qualificações e empregabilidade. In: ALVES, Giovanni. Dimensões da reestruturação produtiva: ensaios de sociologia do trabalho. Londrina: Práxis, 2009.

ARAPIRACA, José O. A USAID e a educação brasileira: um estudo a partir de uma abordagem crítica do capital humano. 273f. Dissertação (Mestrado em Educação) - Instituto de Estudos Avançados em Educação, Fundação Getúlio Vargas, Rio de Janeiro, 1979.

AUROUX, Sylvain. A revolução tecnológica da gramatização. Campinas: Editora da Unicamp, 2009.

BIREME/OPAS/OMS (BIBLIOTECA REGIONAL DE MEDICINA/ ORGANIZAÇÃO PAN-AMERICANA DA SAÚDE/ORGANIZAÇÃO MUNDIAL DA SAÚDE). Sobre a Bireme. História. 2015. Disponível em: <http://www.paho.org/bireme/ index.php?option $=$ com_content $\&$ view $=$ art icle $\& i d=33 \&$ Itemid $=43 \&$ lang $=p t>$. Acesso em: 12 nov. 2015 .

BIREME/OPAS/OMS (BIBLIOTECA REGIONAL DE MEDICINA/ ORGANIZAÇÃO PANAMERICANA DA SAÚDE/ORGANIZAÇÃO MUNDIAL DA SAÚDE). Bireme: situação atual e perspectivas. 2018. Disponível em: $<$ https://www.slideshare.net/Rede_BVS/ bireme-situao-atual-e-perspectivas $>$. Acesso em: 5 jun. 2018.
DECS (DESCRITORES EM CIÊNCIAS DA SAÚDE). Site. 2015. Disponível em: <http://decs.bvs. br/>. Acesso em: mar. 2016.

FEPAFEM (Federación Panamericana de Asociasiones de Facultades y Escuelas de Medicina). Disponível em: <http://www.fepafempafams. org/home/quienes_somos.html >. Acesso em: 20 nov. 2015.

FRIGOTTO, Gaudêncio. Novos fetiches mercantis da pseudoteoria do capital humano do capitalismo tardio. In: ANDRADE, Juarez de; PAIVA, Lauriana G. (orgs.). As políticas públicas para a educação no Brasil contemporâneo: limites e contradições. Juiz de Fora: EdUFJF, 2011. p. 18-35. Disponível em: <https://oebiear. files.wordpress.com/2015/03/as-polc3adticaspc3bablicas-para-a-educac3a7c3a3o-no-brasilcontemporc3a2neo-limites-e-contradic3a7c3b5es. pdf $>$. Acesso em: 2 jun. 2018.

FRIGOTTO, Gaudêncio. A produtividade da escola improdutiva 30 anos depois: regressão social e hegemonia às avessas. Trabalho Necessário, Niterói, v. 13, n. 20, p. 206-233, 2015. Disponível em: <http:// www.uff.br/trabalhonecessario/>. Acesso em: 29 jan. 2016.

GUIMARÃES, Nadya A. Qualificação como relação social. In: PEREIRA, Isabel B.; LIMA, Júlio C. F. (orgs.). Dicionário da educação profissional em saúde. 2. ed. rev. e aum. Rio de 
Janeiro: Escola Politécnica de Saúde Joaquim Venâncio/Fundação Oswaldo Cruz, 2009.

HARVEY, David. O neoliberalismo: história e implicações. São Paulo: Loyola, 2010.

KUENZER, Acacia Z. Da dualidade assumida à dualidade negada: o discurso da flexibilização justifica a inclusão includente. Educação e Sociedade, Campinas, v. 28, n. 100 (especial), p. 1.153-1.178, out. 2007. Disponível em: <http:// www.scielo.br/readcube/epdf.php?doi $=10.1590 /$ S0101-73302007000300024\&pid=S0101 73302007000300024\&pdf_path=es/v28n100/ a2428100.pdf\&lang=pt > . Acesso em: 3 set. 2014.

LANCASTER, Frederick. Indexação e resumos: teoria e prática. Tradução de Antonio Agenor Briquet de Lemos. 2. ed. rev. atual. Brasília: Briquet de Lemos, 2004.

LIMA, Nísia T. O Brasil e a Organização PanAmericana da Saúde: uma história de três dimensões. In: FINKELMAN, Jacobo (org.). Caminhos da saúde pública no Brasil. Rio de Janeiro: Editora Fiocruz, 2002.

MARX, Karl; ENGELS, Friedrich. Manifesto comunista. Tradução de Álvaro Pina e Ivana Jinkings. São Paulo: Boitempo, 1998.MOTTA, Vânia C. Educação e capital social: orientações dos organismos internacionais para as políticas públicas de educação como mecanismos de alívio à pobreza. In: ANDRADE, Juarez de; PAIVA, Lauriana G. (orgs.). As politicas públicas para a educação no Brasil contemporâneo: limites e contradições. Juiz de Fora: EdUFJF, 2011. p. 36-55. Disponível em: <https://oebiear. files.wordpress.com/2015/03/as-polc3adticaspc3bablicas-para-a-educac3a7c3a3o-no-brasilcontemporc3a2neo-limites-e-contradic3a7c3b5es. pdf $>$. Acesso em: 2 jun. 2018.

MÜLLER, Meire T. A educação profissionalizante no Brasil: das corporações de ofícios à criação do Senai. Estudos do Trabalho, São Paulo, ano 3, v. 5, 2009. Disponível em: <http:// www.estudosdotrabalho.org/RevistaRET05. htm>. Acesso em: 24 fev. 2016.
NEVES, Lucia M. W. (org.). Direita para o social e esquerda para o capital: intelectuais da nova pedagogia da hegemonia no Brasil. São Paulo: Xamã, 2010.

NUNES, José H. Dicionários do Brasil: análise e história. Campinas: Pontes, 2006.

NUNES, José Horta. O discurso documental na história das ideias linguísticas e o caso dos dicionários. Alfa: Revista de Linguística, São Paulo, v. 1, n. 52, p.81-100, jan. 2008. Quadrimestral. Disponível em: $<$ https://periodicos. fclar.unesp.br/alfa/article/view/1468/1173>. Acesso em: 30 maio 2017.

ORGANIZAÇÃO PAN-AMERICANA DA SAÚDE/ ORGANIZAÇÃO MUNDIAL DA SAÚDE (OPAS/ OMS). Disponível em: <http://www.paho. org $/$ blogs $/$ nlml 175/?page_id=13>.Acesso em: 17 dez. 2015.

ORLANDI, Eni P. Análise de discurso: princípios \& procedimentos. Campinas: Pontes, 2009.

PAIVA, Carlos H. A. A Organização PanAmericana da Saúde (Opas) e a Reforma de Recursos Humanos na Saúde na América Latina (1960-70). Rio de Janeiro: [s.d.], 2004. Disponível em: <http://observatoriohistoria.coc. fiocruz.br/local/File/opas.pdf $>$. Acesso em: 2 jun. 2015.

PÊCHEUX, Michel. O mecanismo do (des) conhecimento ideológico. In: ZIZEK, Slavoj (org.). Um mapa da ideologia. Rio de Janeiro: Contraponto, 1996. p. 143-152.

PÊCHEUX, Michel. Ler o arquivo hoje. In: ORLANDI, Eni P. (org.). Gesto de leitura: da história no discurso. Campinas: Editora da Unicamp, 1997.

PÊCHEUX, Michel. Semântica e discurso: uma crítica à afirmação do óbvio. Tradução de Eni Pucinelli Orlandi et al. 4. ed. Campinas: Editora da Unicamp, 2009.

PIRES, Denise E. Divisão social do trabalho. In: PEREIRA, Isabel Brasil; LIMA, Julio C. F. (org.) 
Dicionário da Educação Profissional em Saúde. 2. ed. rev. e aum. Rio de Janeiro: Fundação Oswaldo Cruz; Escola Politécnica de Saúde Joaquim Venâncio, 2009. Disponível em: <http://www. epsjv.fiocruz.br/dicionario/ index.html>. Acesso em: 28 abr. 2018.

PIRES-ALVES, Fernando A. Cooperação internacional e informação em ciências da saúde na América Latina - 1967/1982: a Bireme em perspectiva histórica. ENCONTRO REGIONAL DE HISTÓRIA, 12.: USOS DO PASSADO. Anais... Anpuh: Santos, 2006. Disponível em: $<$ http://docplayer.com.br/14331126-Cooperacaointernacional-e-informacao-em-ciencias-dasaude-na-america-latina-1967-1982-a-biremeem-perspectiva-historica.html>. Acesso em: 2 jun. 2015.

PIRES-ALVES, Fernando A.; PAIVA, Carlos H. A. Pós-guerra, Estado de bem-estar e desenvolvimento. In: PONTES, Carlos F.;
FALLEIROS, Ialê (orgs.). Na corda bamba de sombrinha: a saúde no fio da história. Rio de Janeiro: Fiocruz/EPSJV/COC, 2011.

ROMANELLI, Otaíza O. História da educação no Brasil (1930/1973). Petrópolis: Vozes, 1998.

STRECKER, Marcos. Grupos de ensino enfrentam desafio de se adaptar à crise e à queda do Fies. Folha de S. Paulo, São Paulo, 12 nov. 2015. Disponível em: <http://wwwl.folha. uol.com.br/mercado/2015/11/1704925-gruposde-ensino-enfrentam-desafio-de-se-adaptara-crise-e-a-queda-do-fies.shtml > . Acesso em: 2 jun. 2015

Recebido em 12/06/2017. Aprovado em 18/12/2017. 